WORK \& STRESS, 1995, vOL. 9, NO. 4, 513-527

\title{
Performance and burnout in intensive care units
}

\section{GER J. KEIJSERS}

Netherlands Institute of Care and Welfare, PO Box 19152, 3501 DD Utrecht, The Netherlands

\author{
WILMAR B. SCHAUFELI and PASCALE M. LE BLANC \\ Department of Psychology, Utrecht University, PO Box 80.140, 3508 TC Utrecht, \\ The Netherlands
}

\section{CARMEN ZWERTS}

Department of Psychology, University of Nijmegen, The Netherlands

\section{DINIS REIS MIRANDA}

Department of Surgery, University Hospital, Groningen, The Netherlands

Keywords: Performance measures; Intensive Care ; Nurses; Burnout.

The relationship between three different performance measures and burnout was explored in 20 Dutch Intensive Care Units (ICUs). Burnout (i.e. emotional exhaustion and depersonalization) proved to be significantly related to nurses' perceptions of performance as well as to objectively assessed unit performance. Subjective performance measures relate negatively to burnout levels of nurses, whereas an objective performance measure relates positively to burnout. Furthermore, subjectively assessed personal performance (i.e. personal accomplishment) is more strongly related to burnout than subjectively assessed unit performance. A model test of the relationship between both types of subjective performance and burnout reveals that nurses' perception of unit performance is indirectly related to burnout through perception of personal performance. This model holds similarly for objectively well- and poor-performing ICUs.

\section{Introduction}

For a long time occupational burnout has been recognized to be a problem in Intensive Care Units (ICUs) (Lewandowski and Kositsky 1983). Attention has been focused primarily on its organizational antecedents such as excessive workload (Caldwell and Weiner 1982), conflicts among ICU-staff (Oskins 1979), lack of social support (Cronin-Stubbs and Rooks 1985), negative perceptions of the work environment (Stone et al. 1984, Chiriboga and Bailey 1986), and confrontation with patient death and severe illness (Dewe 1988, Mallett et al. 1991). Three types of moderating factors in the antecedent-burnout chain have been identified: (1) personality characteristics, such as self-esteem (Buunk et al. 1994) and hardiness (Topf 1989); (2) environmental factors, such as perceived control (Landsbergis 1988); (3) way of coping with stress (Caldwell and Weiner 1981, Stone et al. 1984, Chiriboga and Bailey 1986, Ehrenfeld and Cheifetz 1990). It appears from these studies that 
nurses with low levels of self-esteem and hardiness, who perceive little environmental control, and who tend to use passive rather than active coping styles, report higher levels of burnout.

The present study investigates the relation between several performance indicators and burnout, whereby subjective performance indicators are regarded as antecedents, and objective performance is regarded as a consequence of nurse burnout in ICUs. Although several authors speculated that burnout results in poor quality of ICU care (Wimbush 1983, Cronin-Stubbs and Rooks 1985, Chiriboga and Bailey 1986, Ehrenfeld 1990), empirical evidence is still lacking. Some studies have been carried out on organizational performance in ICUs (Roelens 1983, Randall and Scott 1988), but their results are inconsistent. For instance, Randall and Scott (1988) found that burnout was associated with poor performance among ICU nurses, whereas Roelens (1983) reported the opposite: low levels of burnout were associated with poor performance in ICU nurses as well as in operating room nurses. However, both studies employed a subjective measure of performance (that is, nurses' perception). Golembiewski and Munzenrider (1988, pp. 84-107) investigated the relation between burnout and performance using both subjective and multiple objective measures. They found that objectively assessed productivity of public social service workers (i.e. headquarters' performance ratings, clients' assessment of quality of services, and effectiveness in terms of man-hour consumption per service produced) was significantly lower in departments where over $50 \%$ of the workers were burned out, compared to departments where fewer workers were burned out. Furthermore, workers' self-rated performance was much more strongly related to burnout than to the objective performance measures.

In sum, investigations on the relationship between burnout and performance in human services settings are scarce and have yielded inconsistent results, probably because they have relied almost exclusively on self-reports. Before discussing the burnout-performance relationship in more depth, attention is paid to the burnout concept and to different types of performance assessment.

\subsection{The conceptualization of burnout}

Burnout is conceived as a multidimensional phenomenon, a set of negative psychological experiences, reflecting a 'wearing out' from prolonged exposure to the stresses of contactintensive occupations (Maslach 1993). In most studies burnout is measured with the Maslach Burnout Inventory (MBI) (Maslach and Jackson 1986). This 22-item self-report instrument assesses three dimensions: (1) Emotional exhaustion - the draining of emotional resources; (2) Depersonalization-a callous and cynical attitude towards the recipients of one's care; (3) Personal accomplishment-work-related competence. High levels of emotional exhaustion and depersonalization and a diminished sense of personal accomplishment are indicative of burnout.

Recently, this popular three-dimensional conceptualization has been challenged on conceptual grounds (Shirom 1989, Koeske and Koeske 1989). According to these critics, emotional exhaustion is the core symptom of burnout, whereas depersonalization and particularly reduced personal accomplishment are additional accompanying variables. This view agrees with the literature review of Schaufeli et al. (1993), who concluded that emotional exhaustion was the dominant burnout-dimension that relates most strongly and consistently with various job stressors and outcome measures such as workload, role problems, absenteeism, and turnover. Early conceptualizations of burnout suggested that depersonalization is a way of coping with the emotional demands of the job (Maslach 1982). For instance, by developing a negative and cynical attitude towards patients, nurses create a psychological distance that protects them from further depleting their emotional 
resources. Recently, Leiter (1993) found empirical evidence for a 'developmental process model of burnout' among human services professionals. This model assumes that job stressors (e.g. workload and interpersonal problems) lead to emotional exhaustion, which in turn brings about depersonalization, indeed suggesting that professionals attempt to gain emotional distance from recipients as a way of coping with their feelings of exhaustion. Interestingly, reduced personal accomplishment is not directly related to both the other burnout dimensions; instead it develops in parallel with emotional exhaustion and depersonalization. Leiter's model agrees with other conceptualizations of burnout, in which particularly reduced personal accomplishment is considered to be a somewhat remote accompanying variable instead of a constituting component of the burnout syndrome (Shirom 1989, Koeske and Koeske 1989).

Following Leiter (1993), the present study regards emotional exhaustion and depersonalization as two related dimensions of the burnout syndrome, representing the affective strain and attitudinal component of the syndrome, respectively. This agrees with Green et al. (1991), who have proposed a composite emotional exhaustion and depersonalization score on the MBI to measure burnout (i.e. the Core of Burnout Scale).

\subsection{Subjective and objective performance indicators}

The present study includes three performance indicators: (1) perceived personal (i.e. subjective) performance; (2) perceived ICU performance; and (3) objective ICU performance. More particularly, in the present study personal accomplishment was used as an indicator of subjective personal performance. The personal criterion of reference can be judged from the content of items such as, 'I deal very effectively with the problems of my patients', 'I feel I'm positively influencing other people's lives through my work', and 'I have accomplished worthwhile things in this job'. Personal performance was contrasted with another perceptual measure, that uses an organizational reference criterion instead of a personal criterion. Example items illustrating the organizational criterion are: 'Our unit almost always meets its patient care treatment goals' and 'Our unit does a good job of applying the most recently available technology to patient care needs'. It is expected that nurses' perceptions of their personal and their unit's performance are similar in direction, although they are not necessarily identical. For instance, Maslach (1982) claimed that human services professionals blame themselves disproportionally for the ineffectiveness of their teams. On the other hand, it is likely that the success of the team is also disproportionally acclaimed by individual nurses (i.e. attributed to one's personal performance).

Both subjective measures were contrasted with an objective measure of unit performance. Following Frese and Zapf (1988), subjective measurement was defined as being tied to an individual's cognitive and emotional processing, whereas in objective measurement an individual's cognitive and emotional processing does not influence the reporting of social and physical facts. To date, very few studies on stress and performance have used objective performance indicators. As far as nursing is concerned, only one study has included an objective indicator of unit performance: frequency of malpractice claims (Jones $e t$ al. 1988). The study showed that stress levels of medical personnel were higher in departments where more claims were reported. Since subjective performance measures are vulnerable to perceptual distortion, they are often very weakly related to objective measures (Alexander and Wilkins 1982). Especially in ICUs such poor relationships might be expected, since nurses' perception of unit performance is based on direct observations that are likely to be biased. For instance, the actual mortality that is observed by nurses and which is likely to influence their subjective sense of performance is a poor indicator for objective performance, 
since older and more severely ill patients are more likely to die. Accordingly, a subjectively poor performing ICU (where many patients die) might turn out to be an ICU where patients with higher objective risks (e.g. age and severity of illness) are hospitalized.

\subsection{The burnout-performance relationship}

At least three kinds of explanations are proposed to explain the general assumption that prolonged job stress and burnout result in poor performance. First, the burnoutperformance relationship can be mediated by another factor. For instance, Motowidlo et al. (1986) emphasize the mediating role of depression. In their view, burnout leads to depression, which in turn has a negative impact on performance. In a similar vein, Maslach (1982) suggested that declining motivation plays a mediating role. This is supported by Stone et al. (1984), who reported that burned out nurses tend to see their work environment as inefficient in getting things done. The authors suggest that this could lead to loss of motivation, and subsequently to decreased performance.

A second tentative explanation is offered by Cohen (1980), who reviewed laboratory studies on the stress-performance relationship. He formulated the adaptive-cost hypothesis, stating that the adverse effects of stress result from the cumulative costs of adapting to stress. This view is compatible with Jamal (1984), who suggested that coping with stress drains nurses' energy that is needed to perform well on the job.

Finally, Golembiewski and Munzenrider (1988) have stressed the importance of recipients' response in health care settings. They reasoned that it is likely that a negative psychological climate arises in units where many workers are burned out. As a consequence, this climate may adversely affect recipients' response to medical treatment, which results in decreased medical performance. These three explanations all pertain primarily to objective performance. Unfortunately, firm empirical evidence is lacking for each of these explanations.

Mostly, poor performance is assumed to be a consequence of burnout. However, the authors believe that a more complex relationship between performance and burnout is plausible. First, there is some cross-sectional evidence that burnout is positively related to lack of competence (Dolan and Renaud 1992), poor self-efficacy (Chwalisz et al. 1992), guilt (Weinberg et al. 1983), and self-blame (Wade et al. 1986). Therefore, it cannot be ruled out that poor performance, which is reflected subjectively by doubts about one's competence, poor self-efficacy, guilt and self-blame, is a precursor of burnout. Moreover, it is important to draw attention to the distinction between objective and subjective performance. It can be speculated that poor subjective performance is an antecedent of burnout, whereas poor objective performance is a consequence of burnout. It is not likely that poor objective performance acts as a precursor of burnout, since this organizational parameter-by its nature - is not part of nurses' psychological environment. For individual nurses it is impossible to collect and analyse all data that are necessary to assess their unit's objective performance. Nevertheless, objective and subjective performance are not completely unrelated, because it can be expected that a unit's objective performance is reflected to a certain extent by nurses' subjective performance and vice versa (Alexander and Wilkins 1982, Hoffman et al. 1991).

To sum up, the authors' view implies that perception of poor performance leads to burnout, which in turn influences objective performance negatively.

The purpose of this study was two-fold. First, the relationships between three performance measures (i.e. perceived personal performance, perceived unit performance, and objective unit performance) were studied. It was expected that the three measures are weakly positively interrelated. Second, the relationships of burnout (i.e. emotional 
exhaustion and depersonalization) with the three performance measures were studied. It was hypothesized that burnout is related to poor (subjective and objective) performance.

\section{Method}

\subsection{Subjects}

The 20 ICUs included in this study are part of a larger study in which 36 Dutch ICUs participated. Three of these units were excluded from the analyses, because they turned out to be medium care units. In 13 out of the remaining 33 ICUs less than 200 patients were admitted during the seven months prior to the survey. A minimum of 200 patient admissions per ICU is needed in order to calculate a unit's objective performance score (Reis Miranda and Spangenberg 1992). Accordingly, 20 ICUs remained of which 576 nurses returned their questionnaires (response rate $75 \%$ ). The scores of these nurses were compared to those of 142 nurses from the 13 ICUs that were not included in the present sample. Note that the ICUs that did not reach the 200 admissions criterion are likely to be smaller, which explains the relatively small number of respondents. No significant differences were found for age, gender, work experience, proportion of registered nurses, levels of burnout, and perceived individual and unit performance. The present sample consisted of $43 \%$ male and $57 \%$ female nurses, of whom about $60 \%$ worked full time. The mean age of the sample was 33.4 years $(\mathrm{SD}=5.53)$. About $90 \%$ were registered as ICUnurses.

\subsection{Measures}

Burnout was assessed by two sub-scales of the Maslach Burnout Inventory (Maslach and Jackson 1986): Emotional Exhaustion (EE, 9 items) and Depersonalization (DP, 5 items). Scores range from never (0) to every day (6). Recently, Schaufeli and Van Dierendonck (1993) showed that the reliability and construct validity of the Dutch version are similar to those of the original American version. In the current sample, the internal consistency of EE was satisfactory (Cronbach's $\alpha=.84$ ), whereas the value for DP was slightly lower $(\alpha=.63)$. Most probably this was due to the relatively small number of items included.

Perceived personal performance was measured by the Personal Accomplishment scale (PA, 8 items) of the MBI ( $\alpha=.74)$. Perceived ICU performance was measured by a scale developed by Shortell et al. (1991). For psychometric reasons, three items had to be deleted. The remaining 5 items constituted an internally consistent scale $(\alpha=.70)$.

Objective ICU performance was assessed by the ratio of actual versus predicted death rates. This so-called Standardized Mortality Ratio (SMR) is used as an estimate of institutional mortality performance (Reis Miranda and Spangenberg 1992, p. 121). The predicted death rate is derived from the 'Acute Physiology and Chronic Health Evaluation' (APACHE III) predictive equations that are based on a pool that includes over 17000 American ICU patients (Zimmerman 1989). APACHE III is designed to provide accurate relative risk stratification for acutely ill hospitalized adults with medical and surgical diagnoses. The APACHE III score consists of a cardinal index risk number varying from 0-299 points. Points are tabulated from weights assigned to acute physiological derangements $(0-252$ points); significant co-morbidities influencing a patient's immunological status (0-23 points) ; and a patient's chronological age (0-24 points). Hence, SMR is an indicator of ICU performance that is adjusted for several patient characteristics such as severity of illness, age, chronic health status, and medical diagnosis.

Data were collected by ICU employees, who recorded medical data from 8111 patients from February to August 1990. Patients' scores were aggregated to a unit score. For the 
purpose of this study SMR-scores have been reversed, so that scores greater than 1.0 indicate good performance (i.e. the actual death rate is smaller than the predicted death rate).

\section{Results}

\subsection{ICU performance}

Contrary to expectations, objective and perceived unit performance were weakly negatively interrelated (table 1). Both subjective performance measures were more strongly and positively interrelated. Finally, objective ICU performance and perceived personal performance were unrelated.

Additionally, the ICUs were divided into objectively well $(n=9)$ and poor $(n=11)$ performing units by employing a median split on the SMR scores. Nurses' perceived unit performance was significantly higher in poor performing ICUs compared to better performing units $(F(1,539)=22.38 ; p<.001)$, whereas no significant difference was found in levels of perceived personal performance $(F(1,539)=1.72 ; N S)$. The difference in levels of perceived unit performance cannot be attributed to differences in staff quality or quality of equipment, as no significant differences were observed between the objectively well- and poor-performing units as far as nurses' age, work experience, proportion of registered nurses and quality of equipment (e.g. mechanical ventilation devices) was concerned.

Table 1. Descriptive statistics for all research variables.

\begin{tabular}{|c|c|c|c|c|c|c|c|}
\hline & \multirow[b]{2}{*}{ Mean } & \multirow[b]{2}{*}{$\mathrm{SD}$} & \multirow[b]{2}{*}{$n$} & \multicolumn{4}{|c|}{ PM correlations } \\
\hline & & & & 2 & 3 & 4 & 5 \\
\hline \multicolumn{8}{|l|}{ Burnout } \\
\hline Emotional exhaustion & 15.40 & 6.97 & 557 & $.48 \star \star$ & $.15^{\star \star}$ & $-.25^{\star \star}$ & $-.42^{\star \star}$ \\
\hline Depersonalization & 7.19 & 3.65 & 555 & & .06 & $-.23 \star \star$ & $-.43 \star \star$ \\
\hline \multicolumn{8}{|l|}{ Performance measures } \\
\hline Objectivef performance (unit) & 1.23 & 0.44 & 23 & & & $-.16^{\star \star}$ & -.01 \\
\hline Perceived unit performance & 10.20 & 1.66 & 556 & & & & $.37 \star \star$ \\
\hline Perceived personal performance & 30.43 & 4.31 & 545 & & & & \\
\hline
\end{tabular}

${ }^{\star} p \leqslant .05 ;{ }^{\star \star} p \leqslant .01 ; \star \star \star p \leqslant .001$

$\dagger$ All nurses working in a particular ICU were assigned the objective performance rating of that ICU.

Table 2. MANOVA results ( $F$-values) with performance measures as independent variables (PP, $\mathrm{UP}$ and $\mathrm{OP}$ ) and burnout (emotional exhaustion and depersonalization) as dependent variables.

\begin{tabular}{|c|c|c|c|}
\hline \multirow[b]{2}{*}{ Performance } & \multicolumn{3}{|c|}{ Burnout } \\
\hline & $\begin{array}{l}\text { Emotional } \\
\text { exhaustion } \\
\text { DF }(1,528)\end{array}$ & $\begin{array}{c}\text { Depersonalization } \\
\text { DF }(1,528)\end{array}$ & $\begin{array}{c}\text { Multivariate } \\
\text { DF }(2,527)\end{array}$ \\
\hline \multicolumn{4}{|l|}{ Main effects } \\
\hline Personal Performance (PP) & $67.55^{\star \star \star}$ & $62.43 \star \star \star$ & $46.81 \star \star \star$ \\
\hline Perceived Unit Performance (UP) & $4.98^{\star}$ & 1.27 & 2.52 \\
\hline Objective Unit Performance (OP) & $12.05 \star \star \star$ & $6.88 \star \star$ & $6.98 \star \star \star$ \\
\hline \multicolumn{4}{|l|}{ Interactions } \\
\hline$P P \times U P$ & 0.61 & 1.95 & 1.01 \\
\hline $\mathrm{PP} \times \mathrm{OP}$ & 0.53 & 0.76 & 0.47 \\
\hline $\mathrm{UP} \times \mathrm{OP}$ & 0.00 & 0.44 & 0.25 \\
\hline $\mathrm{PP} \times \mathrm{UP} \times \mathrm{OP}$ & $4.30^{\star}$ & 2.80 & 2.59 \\
\hline
\end{tabular}

${ }^{\star} p \leqslant .05 ;{ }^{\star \star} p \leqslant .01 ;{ }^{\star \star \star} p \leqslant .001$ 
To summarize: contrary to expectations, objective performance was found to be negatively related to perceived unit performance, whereas no relationship existed with perceived personal performance. Only the (positive) relationship between the two subjective performance measures was significant and in the expected direction.

\subsection{Burnout and performance}

As expected, both subjective performance measures correlated negatively with the two burnout indicators (table 1). The relationships were somewhat stronger for perceived personal performance than for perceived unit performance. Furthermore, only emotional exhaustion showed a significant zero-order correlation with objective performance. However, contrary to expectations this relation was positive: the better the objectively measured performance of the ICUs, the higher the burnout levels that were reported by the nurses. Again, the objectively well- and poor-performing ICUs were compared. As could be expected, the finding that nurses in well-performing ICUs showed more burnout symptoms than in poor-performing units $(F(2,549)=7.94 ; p<.001)$ was confirmed.

In order to study the relationships between performance and burnout more closely, a $2 \times 2 \times 2$ MANOVA was conducted with perceived personal performance (high/low), perceived unit performance (high/low), and objective performance (high/low) as independent variables, and burnout (i.e. emotional exhaustion and depersonalization) as dependent variable. The levels of the independent variables were created by employing a median split. In addition to testing the main effects of each performance measure, this design also allows for testing interaction effects of the independent measures.

The main effects of perceived personal performance and objective performance on burnout were significant (table 2). Nurses who reported high levels of personal performance had lower burnout levels than nurses who rated their personal performance lower (table 3 ). This applied to emotional exhaustion as well as to depersonalization. The reverse was true for objective performance: in better performing ICUs nurses experienced more feelings of exhaustion and depersonalization than in poorer performing units. As far as perceived unit performance was concerned, only one significant univariate effect of emotional exhaustion was observed: nurses who perceived their units to perform better showed lower burnout levels than nurses who perceived their units to perform less well.

No significant multivariate interaction effects of the three performance measures were observed. Only a univariate second order interaction effect on emotional exhaustion was found (figure 1). For the interpretation of this rather complex interaction effect, it is crucial to distinguish between balanced and unbalanced perceptions of personal and unit performance. In the former case, both indicators of subjective performance are likewise rated high or low. In the latter case, a discrepancy exists since one indicator is rated low whereas the other is rated high, or vice versa. When the perceptions of performance are balanced, the objective level of performance does not matter. That is, when subjective (personal and unit) performance is poor, the level of emotional exhaustion is high, whereas the level of emotional exhaustion is low when subjective performance is high, irrespective of the objective level of performance. On the other hand, when perceptions of performance are unbalanced, objective performance plays a negative role. That is, in objectively wellperforming units, nurses with unbalanced performance perceptions show higher levels of emotional exhaustion, particularly when they perceive their personal performance to be low compared with unit performance.

Accordingly, a refinement had to be made concerning the earlier finding that objective performance and emotional exhaustion are inversely related (table 1). More detailed analysis showed that this was only true when nurses' perceptions of their own performance 


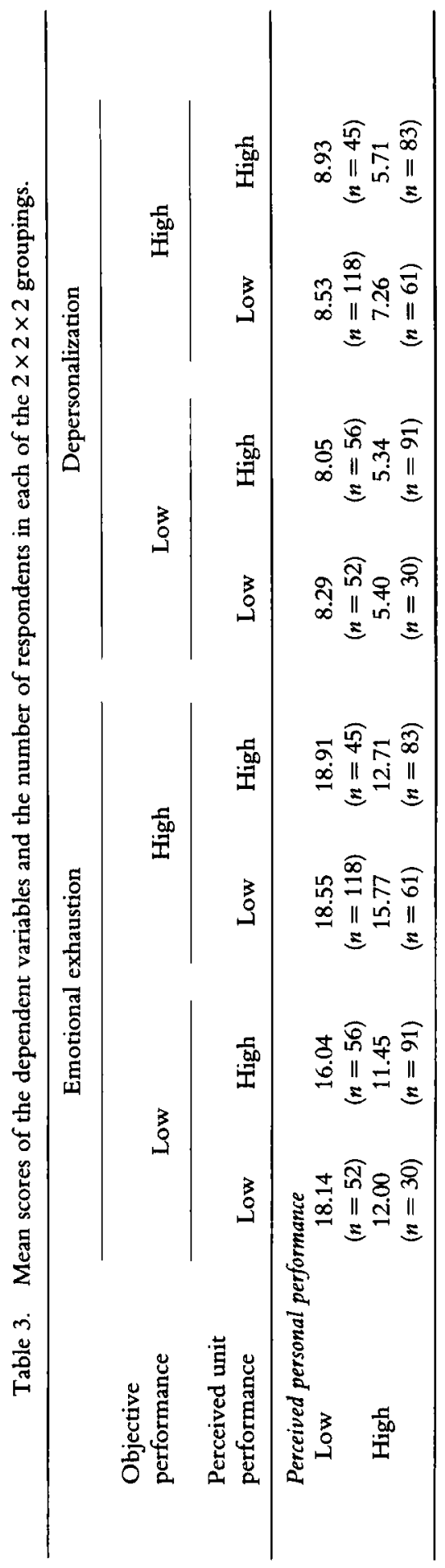




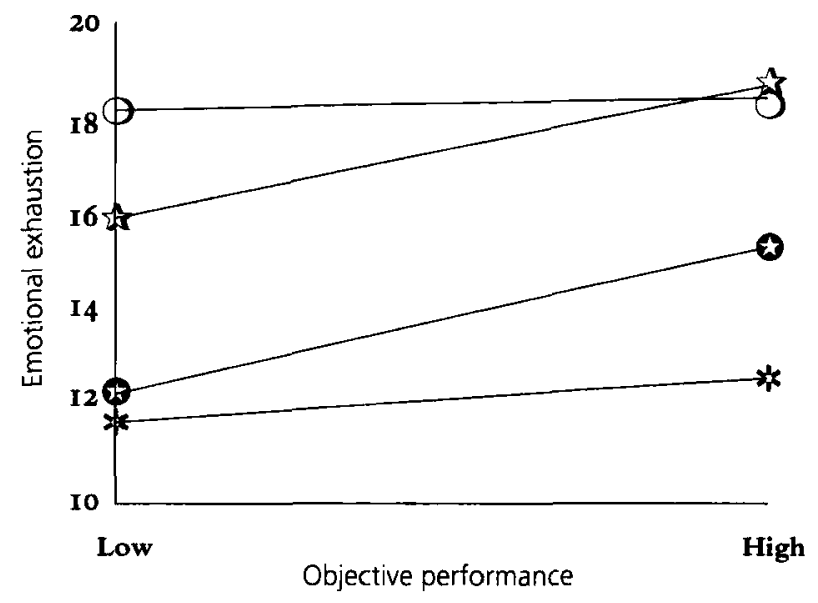

O UP-/PP- $\quad$ is UP+/PP- UP-/PP+ $\quad$ * UP+/PP+

Figure 1. Three-way interaction effect between subjective and objective performance measures on emotional exhaustion. $\mathrm{UP}=$ subjective unit performance; $\mathrm{PP}=$ subjective personal performance.
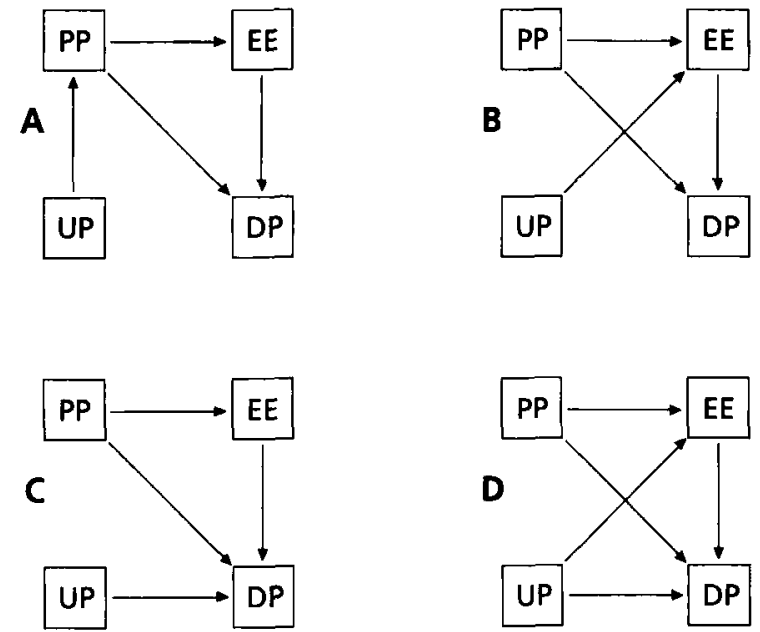

Figure 2. A priori models for the burnout-subjective performance relationships. EE $=$ emotional exhaustion; $\mathrm{DP}=$ depersonalization; $\mathrm{PP}=$ subjective personal performance; $\mathrm{UP}=$ subjective unit performance.

and their units' performance were unbalanced. Particularly, those nurses who were employed in objectively and subjectively well-performing ICUs, but who-at the same time-felt that they were personally not performing quite well, felt exhausted. On the other hand, nurses who worked in objectively and subjectively well-performing ICUs, and who felt that they were doing well, showed the lowest levels of exhaustion.

\subsection{Burnout and subjective performance}

In order to explore the relationships between burnout and subjective performance in greater detail, LISREL VII was used to test competing linear structural models. Following Leiter's (1993) developmental process model of burnout, depersonalization is considered to be a way of coping with emotional exhaustion. However, diverging from Leiter's model, 
Table 4. Goodness-of-fit tests for the models in figure 3 for 'low objective performance' (low OP) and 'high objective performance' (high OP) units.

\begin{tabular}{lccccccc}
\hline & $D F$ & $\chi^{2}$ & $p$ & GFI & AGFI & Rmsr & NFI \\
\hline $\begin{array}{l}\text { Model A } \\
\text { low OP }\end{array}$ & 2 & 2.61 & .27 & .99 & .97 & .03 & .99 \\
$\quad$ high OP & 2 & 3.58 & .17 & .99 & .97 & .03 & .98 \\
$\begin{array}{l}\text { Model B } \\
\quad \text { low OP }\end{array}$ & 2 & 36.72 & .00 & .93 & .65 & .14 & .80 \\
$\quad$ high OP & 2 & 44.88 & .00 & .94 & .68 & .14 & .76 \\
$\begin{array}{l}\text { Model C } \\
\text { low OP }\end{array}$ & 2 & 38.49 & .00 & .93 & .64 & .16 & .80 \\
$\quad$ high OP & 2 & 44.64 & .00 & .84 & .68 & .14 & .77 \\
$\begin{array}{c}\text { Model D } \\
\text { low OP }\end{array}$ & 1 & 36.30 & .00 & .93 & .32 & .15 & .81 \\
high OP & 1 & 42.97 & .00 & .94 & .39 & .13 & .77 \\
\hline
\end{tabular}

Note. $\quad$ GFI $=$ Goodness-of-fit index; AGFI $=$ Adjusted goodness-of-fit index $;$ Rmsr $=$ Root mean square residual $; \mathrm{NFI}=$ Normed fit index .

but based on the authors' prior reasoning and on the strong relations found in the previous analyses, poor subjective performance was considered to be a precursor of burnout. Since the authors' subjective personal performance measure (i.e. personal accomplishment) is traditionally considered to be part of the burnout syndrome, it is plausible to hypothesize close relationships of it with emotional exhaustion and depersonalization. Based on these assumptions, four hypothetical models were a priori specified (figure 2). Relations between subjective personal performance and burnout were similar across all models. It was assumed that subjective performance was related to depersonalization directly as well as indirectly through emotional exhaustion. However, the role of subjective unit performance differed in each model. Model A assumes that perceived unit performance influences burnout indirectly through perceived personal performance, whereas models $\mathrm{B}, \mathrm{C}$, and $\mathrm{D}$ assume that perceived unit performance has a direct influence on emotional exhaustion, depersonalization, or both burnout dimensions, respectively.

Since previously analyses have shown that the effects of subjectively and objectively assessed performance on burnout interact, the LISREL analyses were carried out separately in objectively poor- $(n=242)$ and objectively well- $(n=334)$ performing ICUs. That is, the fit of each of the four models was computed for poor- and well-performing ICUs separately. Since only one indicator for each variable in the model was available, pathanalysis was employed. This means that only relationships between manifest or observed variables were analysed and no underlying latent variables were included.

Table 4 shows that Model A has the best fit in both subsamples. There was no indication for an interaction effect of subjectively and objectively assessed performance on burnout. The estimated path coefficients (standardized regression coefficients) were quite similar in both subsamples (figure 3). Only the relation between perceived personal performance and emotional exhaustion was somewhat stronger among nurses working in poorlyperforming ICUs.

In order to check if model A was equivalent across well- and poorly-performing ICUs, a multiple group analysis was performed. To test the hypothesis of equivalence, the absolute fit of two models was compared: (1) the model in which the pattern of relationships was constrained to be equal, and (2) the model in which both the pattern of relationships and the path coefficients were constrained to be equal (Byrne et al. 1989). Since the difference in $\chi^{2}$ 


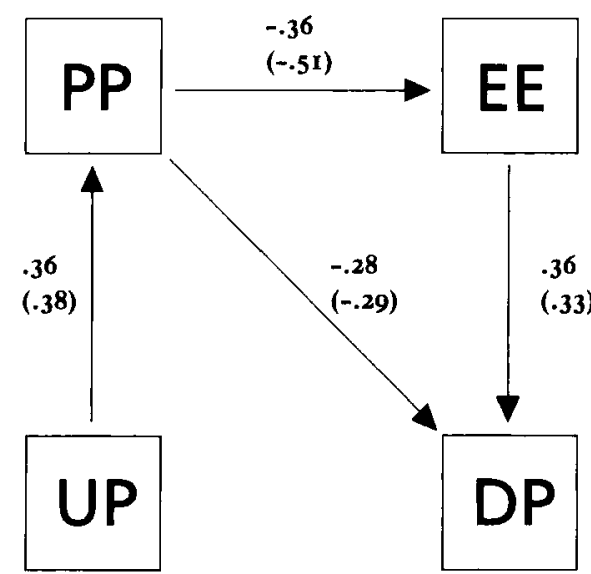

Figure 3. Standardized solutions for Model A in low performance ICUs $(n=11)$ and high performance ICUs $(n=9)$. $\mathrm{EE}=$ emotional exhaustion; $\mathrm{DP}=$ depersonalization; $\mathrm{PP}=$ subjective personal performance; UP = subjective unit performance. Low performance ICUs in brackets.

of these two models was not significant, the hypothesis of equivalence was accepted $\left(\chi^{2}(4)=4.12 ; p=.39\right)$.

To summarize: according to the best fitting model, nurses' perception of unit performance was indirectly related to burnout through the perception of personal performance. This held in objectively poor- and well-performing ICUs alike.

\section{Discussion}

The purpose of this study was two-fold: (1) to investigate the relationships between objective and subjective performance indicators in ICUs; (2) to explore the relationships between both types of performance indicators and burnout. Contrary to expectations both subjective ratings only (i.e. perceived personal and unit performance) were positively interrelated. The relationships with objectively assessed performance were either absent (personal performance) or weakly negative (unit performance).

Also contrary to expectations, burnout was positively related to objective performance: higher burnout levels were found among nurses who worked in objectively better performing units. The negative correlations of the two burnout components with subjective performance were stronger for perceived personal performance than for perceived unit performance. This was not surprising, since some authors consider poor personal performance as a dimension of the burnout syndrome (Perlman and Hartman 1982, Maslach and Jackson 1986). Finally, it was concluded that the perception of unit performance was indirectly related to burnout through the perception of personal performance.

\subsection{Objective and subjective performance}

The absent or weakly negative correlations between subjective and objective unit performance indicate that actual unit performance is not adequately reflected by measures of perceived performance. This might be caused by a so-called ceiling effect, i.e. the lack of extremely well- or extremely poor-performing units. Although SMR scores in the present study varied between .38 and 2.32 , differences in objective performance were probably too small to be noticed by nurses. Accordingly, a unit's objective performance does not play a role in nurses' psychological environment and therefore is not likely to influence subjective performance. 
Another explanation for the low and negative correlations between objective and subjective unit performance is the rather abstract nature of the former. A unit's objective performance score is calculated from a set of statistical parameters that are based on thousands of patients. In contrast, it is likely that nurses base their subjective perceptions of unit performance on their personal observations, such as the actual number of patients dying in the unit. This is supported by Schaufeli et al. (1995), who found a significant positive correlation $(r=.47)$ between subjective unit performance and actual death rates in the ICUs. In short: subjective performance is based on direct observation (i.e. actual mortality), whereas objective performance is based on statistical data that are beyond the observation of individual nurses. Obviously, by standardizing actual mortality rates and transforming them into an abstract figure, the psychological nature of this measure is lost.

Accordingly, objective and subjective performance assess different aspects of performance (Hoffman et al. 1991). In the present study, the objective measure has a quite narrow scope (standardized mortality ratio). On the other hand, the subjective measure of unit performance might also be based on more general aspects, such as observed mortality, discharged patients' quality of life, and catering for patients' needs.

\subsection{Burnout and performance}

These results agree with earlier observations that burnout is more strongly related to selfreported performance measures than to inter-subjective (Lazaro et al. 1985, Randall and Scott 1988) or objective (Golembiewski and Munzenrider 1988) measures. As far as subjective performance measures are concerned these findings could be caused by common method variance. However, in this study a significant relation between burnout and objective performance was also found. Obviously, common method variance cannot be held responsible for this result. Quite surprisingly, however, the relationship is positive: higher objective performance ratings are associated with higher levels of burnout among nurses. On the other hand, as expected, higher perceived personal performance was found to be associated with lower levels of burnout. It can be speculated that both findings have a common cause. For example, the use of sophisticated medical technology in patient care is likely to boost objective performance and, at the same time, to reduce feelings of personal accomplishment. A nurse might evaluate personal performance less favourably because (s)he has to rely more strongly on technology. However, a complete understanding of all parameters to be dealt with is often beyond nurses' training and education (Fitter 1987). Therefore, a highly technological environment is more likely to be stressful and to foster burnout in the long run. For instance, Roelens (1983) observed that ICU nurses who worked in such technological environments were more likely to experience feelings of depersonalization than their colleagues who worked in ICUs where less advanced technology was used. She suggested that nurses who work in environments where attention must be focused on the technological rather than on the human aspect, develop a depersonalized attitude as a coping mechanism in order to survive in such highly technological work-environments.

An alternative explanation could be that non-technological stresses are higher in wellperforming ICUs compared to poorer-performing ICUs. For instance, there is some evidence that in well-performing units leadership and collaboration are perceived to be less favourable (Keijsers et al., submitted) which might contribute to nurses' stress.

In sum : it can be speculated that the use of sophisticated technology is a common cause of improved objective performance as well as reduced personal performance perceptions. 
In this way, intensive use of technology in ICUs might simultaneously enhance performance and increase burnout, particularly feelings of depersonalization. This will be referred to as the 'toll hypothesis' later on.

A final possible explanation for the positive relationship between burnout and objective performance is that higher levels of performance were being attained through nurses overextending themselves. That is, low mortality rates may be found only when nurses work to the point of exhaustion.

\subsection{Subjective personal and subjective unit performance}

The three-way interaction effect that was observed (figure 1) indicates that the relations between objective and subjective performance, and burnout are rather complex. When the perceptions of unit and personal performance are balanced, i.e. both types of performance are perceived as being high or both are perceived as being low, the relation of subjective performance with burnout is clear: poor subjective performance is related to higher levels of burnout. This result suggests that both types of subjective performance have additive stress-buffering effects. It is remarkable that the highest levels of emotional exhaustion were found among nurses who were employed in objectively and subjectively well-performing units, but who felt that they personally were performing poorly. Probably, the fact that one's own poor personal performance cannot be externally attributed to the work environment, and thus is more likely to be internally attributed, is quite stressful and exhausts nurses' emotional resources. This interpretation is supported by models that link specific (i.e. internal) causal attributions to psychological distress, most notably depression (Abramson et al. 1978). These results also show that when perceptions of unit and personal performance were unbalanced, i.e. unit performance was rated low and personal performance was rated high or vice versa, nurses working in objectively well-performing ICUs experienced higher levels of burnout than nurses working in objectively poorperforming ICUs. This finding might be explained straightforwardly by the 'toll hypothesis'. If it is assumed, in accordance with this hypothesis, that stresses are higher in well-performing ICUs than in poor-performing ICUs, it could be argued that higher levels of stress can be buffered less by identical levels of perceived performance. Accordingly, if both types of subjective performance have stress-buffering effects, burnout would be expected to be highest in objectively well-performing ICUs with poor subjective ratings. Again, a ceiling effect could explain why this is not found. Probably, an emotional exhaustion score of, for example, 18 on the MBI is about the limit for Dutch nurses to keep working in an ICU. Higher burnout levels could eventually result in absenteeism or turnover (Firth and Britton 1989).

In conclusion, this study illustrates that both subjective and objective assessments of ICU performance show seemingly paradoxical relations with burnout. As long as the nature of this paradox is not completely understood, one should be extremely cautious when interpreting performance data. Although doubtless tempting, the assumption that subjective performance measures reflect objective performance in one way or another should be avoided. From a scientific point of view, the fact that good objective performance goes along with poor subjective performance and high levels of burnout, may seem counterintuitive, but is inspiring for further research. From a practical point of view, this finding warns us that particular strategies to improve ICU performance, for instance increasing the use of technology, may take a high toll on human resources. 


\section{References}

Agramson, L. Y., Seligman, M. E. P. and Teasdale, J. P. 1978, Learned helplessness in humans: critique and reformulation, Journal of Abnormal Psychology, 87, 49-74.

Alexander, E. R. and Wilkins, R. D. 1982, Performance rating validity: the relationship of objective and subjective measures of performance, Group \& Organization Studies, 7, 485-496.

Buunk, B. P., Schaufeli, W. B. and Ybema, J. F. (1994). Burnout, uncertainty and the desire for social comparison among nurses, Journal of Applied Social Psychology, 24, 1701-1718.

Byrne, B. M., Shavelson, R. J. and Muthén, B. 1989, Testing for the equivalence of factor covariance and mean structures: the issue of partial measurement invariance, Psychological Bulletin, 105, 456-466.

Caldwelt, T. and Weiner, M. F. 1982, Stresses and coping in ICU nursing, General Hospital Psychiatry, 3, 119-127.

Chiriboga, D. A. and Bailey, J. 1986, Stress and burnout among critical care and medical surgical nurses: a comparative study, Critical Care Quarterly, 9, 84-92.

Chwalisz, K., Altmaier, E. M. and Russels, D. W. 1992, Causal attributions, self-efficacy cognitions and coping with stress, Journal of Social and Clinical Psychology, 11, 377-400.

COHEN, S. 1980, Aftereffects of stress on human performance and social behavior: a review of research and theory, Psychological Bulletin, 88, 82-108.

Cronin-Stubbs, D. and Rooks, C. A. 1985, The stress, social support, and burnout of critical care nurses: the results of research, Heart \& Lung, 14, 31-39.

DEWE, P. J. 1988, Investigating the frequency of nursing stressors: a comparison across wards, Social Science \& Medicine, 26, 375-380.

Dolan, S. L. and Renaud, S. 1992, Individual, organizational and social determinants of managerial burnout : a multivariate approach, Journal of Social Behavior and Personality, 7, 95-110.

Ehrenfeld, M. 1990, Israeli nurses in intensive cardiac care units (ICCUs): stress, satisfaction and coping, Intensive Care Nursing, 6, 167-171.

Ehrenfeid, M. and Cheifetz, F. R. 1990, Cardiac nurses: coping with stress, Journal of Advanced Nursing, 15, 1002-1008.

FirTh, H. and Britron, P. 1989, 'Burnout' absence and turnover amongst British nursing staff, Journal of Occupational Psychology, 62, 55-60.

FITTER, M. 1987, The impact of new technology on nurses and patients, in R. Payne and J. FirthCozens (eds), Stress in Health Professionals (Wiley, New York), pp. 211-229.

FRESE, M. and ZAPF, D. 1988, Methodological issues in the study of work stress: objective versus subjective measurement of work stress and the question of longitudinal studies, in C. L. Cooper and R. Payne (eds), Causes, Coping and Consequences of Stress at Work (Wiley, New York), pp. 375-411.

Golembiewski, R. T. and Munzenrider, R. F. 1988, Phases of Burnout. Developments in Concepts and Applications (Praeger, New York).

Green, D. E., W Alkey, F. H. and TAYlor, A. J. W. 1991, The three-factor structure of the Maslach Burnout Inventory, Journal of Social Behavior and Personality, 6, 453-472.

Hofpman, C. C., Nathan, B. R. and Holden, L. M. 1991, A comparison of validation criteria: objective versus subjective performance measures and self- versus supervisor ratings, Personnel Psychology, 44, 601-619.

Jamal, M. 1984, Job stresses and job performance controversy : an empirical assessment, Organizational Behaviour and Human Performance, 33, 1-21.

Jones, J. W., Barge, B,. N., Steffy, B. D. and Fay, L. M. 1988, Stress and medical malpractice: organizational risk assessment and intervention, Journal of Applied Psychology, 73, 727-735.

Keijsers, G. J., Schaufeli, W. B., Reis Miranda, D., Spangenberg, J. F. A., Devers, K. J., Gillies, R. R. and ShORTenL, S. M. Psychological Climate in Intensive Care Units. The Relationships of Staff Interaction with Objective Performance. Manuscript submitted for publication.

Koeske, G. F. and Koeske, R. D. 1989, Construct validity of the Maslach Burnout Inventory: a critical review and reconceptualization, Journal of Applied Behavioral Science, 25, 131-144.

LANDSBERGIS, P. A. 1988, Occupational stress among health care workers: a test of the job demandscontrol model, Journal of Occupational Behavior, 9, 217-239.

Lazaro, C., Shinn, M. and Robinson, P. E. 1985, Burnout, job performance and job withdrawal behaviours, Journal of Health \& Human Resources Administration, 19, 213-234.

LErTER, M. P. 1993, Burnout as developmental process: consideration of models, in W. B. Schaufeli, C. Maslach and T. Marek (eds), Professional Burnout: Recent Developments in Theory and Research ('Taylor \& Francis, Washington), pp. 237-250. 
Lewandowski, L. A. and Kositsky, A. M. 1983, Research priorities for critical care nursing: a study by the American Association of Critical Care Nurses, Heart \& Lung, 12, 35-44.

Maliett, K., Price, J. H., Jurs, S. G. and Slenker, S. 1991, Relationships among burnout, death anxiety, and social support in hospice and critical care nurses, Psychological Reports, 68, $1347-1359$.

MaslaCH, C. 1982, Burnout: a social psychological analysis, in J. W. Jones (ed.), The Burnout Syndrome: Current Research, Theory, Investigations (London House Press, Park Ridge, Ill).

MaslaCh, C. 1993, Burnout: a multidimensional perspective, in W. B. Schaufeli, C. Maslach and T. Marek (eds), Professional Burnout: Recent Developments in Theory and Research (Taylor \& Francis, Washington), pp. 19-32.

Maslach, C. and Jackson, S. E. 1986, The Maslach Burnout Inventory. Manual (Consulting Psychologists Press, Palo Alto).

Motowidlo, S. J., Packard, J. S. and Manning, M. R. 1986, Occupational stress: its causes and consequences for job performance, Journal of Applied Psychology, 71, 618-629.

Oskins, S. L. 1979, Identification of situational stressors and coping methods by intensive care nurses, Heart \& Lung, 8, 953-960.

Perlman, B. and Hartman, A. E. 1982, Burnout: summary and future research, Human Relations, 35 , 283-305.

Randall, M. and Scott, W. A. 1988, Burnout, job satisfaction and job performance, Australian Psychologist, 23, 335-347.

Reis Mrranda, D. and Spangenberg, J. F. A. 1992, Kwaliteit, doelmatigheid en organisatie van intensive care units in Nederland) (Quality, efficiency and organization of intensive care units in the Netherlands) (Foundation for Research on Intensive Care in Europe, Groningen).

Roelens, A. I. 1983, Job stress and burnout among staff nurses in acute care hospitals, Dissertation Abstracts International, $44: 4578$.

Schaufeli, W. B. and VAN Dierendonck, D. 1993, The construct validity of two burnout measures, Journal of Organizational Behavior, 14, 631-647.

Schaufeli, W. B., Enzmann, D. and Girault, N. 1993, Measurement of burnout: a review, in W. B. Schaufeli, C. Maslach and T. Marek (eds), Professional Burnout: Recent Developments in Theory and Research (Taylor \& Francis, Washington), pp. 199-215.

Schaufeli, W. B., Keijsers, G. J. and Reis Miranda, D. (1995). Burnout, technology use, and ICU-performance, in S. L. Sauter \& L. R. Murphy (eds), Organizational Risk Factors for Job Stress (APA Books, Washington), pp. 259-271.

ShIROM, A. 1989, Burnout in work organizations, in C. L. Cooper and I. Robertson (eds), International Review of Industrial and Organizational Psychology (Wiley, New York), pp. 25-48.

Shortell, S. M., Rousseau, D. M., Gillies, R. R., Devers, K. J. and Simons, T. L. 1991, Organizational assessment in intensive care units (ICUs): construct development, reliability and validity of the ICU Nurse-physician Questionnaire, Medical Care, 29, 709-727.

Stone, G. L., Jebsen, P., Walk, P. and Belsham, R. 1984, Identification of stress and coping skills within a critical care setting, Western Journal of Nursing Research, 6, 201-211.

Topf, M. 1989, Personality hardiness, occupational stress, and burnout in critical care nurses, Research in Nursing \& Health, 12, 179-186.

WADE, D. C., COOLEY, E. and SAvirCKI, V. 1986, A longitudinal study of burnout, Children and Youth Services Review, 5, 161-173.

Weinberg, S., Edwards, G. M. and Garove, W. E. 1983, Burnout among employees of state residential facilities serving developmentally disabled persons, Children and Youth Services Review, 5, 239-253.

WimbusH, F. B. 1983, Nurse burnout: its effect on patient care, Nursing Management, 14, 55-57.

Zimmerman, J. E. (ed.) 1989, Apache III study design: analytical plan for evaluation of severity and outcome in intensive care unit patients, Critical Care Medicine, 17, no. 12, part 2: suppl., pp. 169-221.

Revised version submitted: October 1994.

Accepted: February 1995. 